(C) 1981. The Genetical Society of Great Britain

\title{
APOSTATIC SELECTION OF DISTASTEFUL PREY
}

\author{
JEREMY J. D. GREENWOOD, ELIZABETH M. WOOD and SHEILA BATCHELOR \\ Department of Biological Sciences, The University, Dundee DD1 4HN, Scotland
}

Received 6.x.80

\section{SUMMARY}

\begin{abstract}
To account for the usual monomorphism of distasteful animals and of Müllerian mimics, it is commonly suggested that predators take disproportionately more of the rare forms of distasteful prey. Two experiments were carried out to test this hypothesis, each comprising a number of trials in some of which one of two colours of artificial food was the rarer and in others of which the other form was the rarer. In one experiment, using wild passerines, selection was not frequency-dependent. In the other, using domestic chicks, the rarer form was taken disproportionately less than the commoner, contrary to expectation. The conditions under which selection is likely to favour or disfavour the rarer forms in distasteful prey are discussed. Selection favouring the rarer form may account for those unusual cases in which distasteful animals are polymorphic.
\end{abstract}

\section{INTRODUCTION}

IT is a commonplace observation that edible species of animals are often cryptic whereas inedible species are aposematic (see Edmunds, 1974; Curio, 1976; Harvey and Greenwood, 1978 for reviews). Many experiments have shown the selective advantage of crypsis in edible species. Others have shown that predators avoid distasteful, aposematic species, generally by learning but sometimes innately (references in Edmunds, 1974). In distasteful species bright colours appear to be advantageous partly because such colours are markedly different from the cryptic ones which predators associate with edibility (Shettleworth, 1972; Turner, 1975), partly for other reasons (J. J. D. Greenwood, in prep.; Gittleman and Harvey, 1980; Gittleman, Harvey and Greenwood, 1980; J. M. Lambert and J. J. D. Greenwood, in prep.). Some edible species are Batesian mimics, resembling particular aposematic species and therefore being avoided by predators (see Wickler, 1968; Edmunds, 1974; Turner, 1975; Harvey and Greenwood, 1978 for reviews).

In all these cases selection may be frequency-dependent. Selection in edible, non-mimetic species is often apostatic, the predators ignoring the rarer forms (see Murdoch and Oaten, 1975; Greenwood and Elton, 1979, for reviews and Hubbard, Greenwood, Glover and Cook, in prep., for a discussion of the reasons for such behaviour). Such selection tends to maintain polymorphism. Mimetic species may also be polymorphic, with the different morphs resembling different aposematic models. The explanation of this is as follows (e.g., Turner, 1975). If a mimic is rare relative to its model, predators taking an animal showing that colour pattern usually suffer an unpleasant experience, so they avoid that pattern. If, in contrast, a mimic is common relative to its model, predators taking an animal of that pattern usually get a palatable meal, so they may choose not to avoid that pattern. Thus common morphs in a polymorphic mimetic species tend to be at a selective disadvantage. In contrast aposematic, distasteful species 
are usually, though not always, monomorphic (Edmunds, 1974). It is generally accepted that this is because inexperienced predators will eat about the same absolute numbers of two or more inedible forms before learning that they are distasteful and will therefore kill a higher proportion of the rarer forms than of the commoner.

This hypothesis appears to have been tested only once by experiment. Benson (1972) found that predation in the aposematic butterfly Heliconius erato was heavier on individuals painted with a novel colour pattern than on those painted in their usual colours. However, this result may indicate only that the novel colour pattern was a less effective pattern in an absolute sense, not because it was rare. To test the frequency-dependent nature of the selection, one must make experiments in which the effects of specific pattern and of frequency are separated. We report here on two such experiments and show that they lend no support to the hypothesis being tested.

\section{EXPERIMENT ONE}

\section{(i) Methods}

Baits of coloured pastry were presented to wild birds. The pastry was a 2:1 mixture of flour and lard, with $1 \mathrm{ml}$ of tap water added per $9 \mathrm{gm}$ of mixture. Quinine sulphate B.P. was added at a concentration of 0.5 per cent. This made the pastry very distasteful to humans; furthermore, birds learn to avoid food containing this concentration of quinine sulphate (Ford, 1971). The pastry was coloured with tasteless food dyes (Pointing Limited, Prudhoe, Northumberland, England). Sunset Yellow and Cherry Red were used, the exact colour depth being kept constant in different batches by reference to standards. The pastry was cut into $5 \times 5 \times 10 \mathrm{~mm}$ cuboids.

In each trial 400 baits were set out on a lawn in a square grid at intervals of $25 \mathrm{~cm}$. About $20 \mathrm{gm}$ of white bread was broken into small pieces and scattered around the square, to attract feeding birds. After about 4 hours, or before if the baits were being eaten rapidly, the uneaten baits were collected: those bearing beak marks were counted as "killed".

Trials were carried out in simultaneous pairs, one trial with 360 yellow and 40 red baits, the other with the reverse proportions. The positions of the baits were randomised in respect of colour. Ten pairs of trials were carried out over a period of 6 weeks, nine in Dundee (Scotland), one in Lancashire (England). None of the lawns was closer than $400 \mathrm{~m}$ to any of the others, so the birds were probably naive in each trial. The birds that ate the baits were not watched but the common lawn-feeding passerines likely to have been involved are Blackbirds Turdus merula, Starlings Sturnus vulgaris, and House Sparrows Passer domesticus.

\section{(ii) Statistical analysis}

Selection in each trial was measured by the $\beta$ coefficient of Manly $(1973,1974)$. This is based on a model that assumes that the preference of the animals remains constant during the trial, $\beta$ being a measure of that preference in the sense that it is the probability that if the animal was faced with an equal number of the two food types it would take one rather than 
the other. Comparison of the $\beta$ values for different trials enables us to test whether preference was dependent on the relative frequency of the two types of food.

\section{(iii) Results}

Table 1 shows the $\beta$ values. The missing value is the result of all the baits being eaten in this trial. The overall mean value is 0.786 , indicating

TABLE 1

Preference $(\beta)$ for red pastries shown by wild birds in
experiment one

a strong general preference for red $(\beta=1.0$ means that only red were eaten; $\beta=0.5$ means no preference; $\beta=0.0$ means no red eaten). The magnitude of the difference between the $\beta$ values of the two members of each pair of trials is a measure of any frequency-dependent effect. Taking the first nine pairs of trials, this difference is indistinguishable from zero (average 0.030 , s.e. 0.124 ). Thus if selection was frequency-dependent in this experiment, it was only weakly so. The overall preference for red and the variation between trials were much more important.

\section{EXPERIMENT TWO}

\section{(i) Methods}

Male White Leghorn chicks (Gallus galius) were presented with chick crumbs, a commercial rearing diet. The trial crumbs were sieved to restrict the size range to $2 \cdot 0-2.4 \mathrm{~mm}$ minimum diameter. They were coloured dark green or dark brown by spraying them with tasteless food dyes (manufacturer unknown). Some of the crumbs were made distasteful by adding $1.5 \mathrm{gm}$ mustard powder and $1 \mathrm{gm}$ quinine sulphate per $100 \mathrm{ml}$ of dye. The crumbs for the whole experiment were prepared in a single batch and there were no detectable differences in colour between edible and distasteful crumbs.

A randomised block design was used for the experiment, the four blocks being successive weeks. Day-old chicks were obtained on day 1 and kept in a single box until day 4 . They were then transferred to individual cardboard boxes, in which they were to be tested on day 7. Most of these 
boxes had floors of $28 \times 28 \mathrm{~cm}$ and walls of $31 \mathrm{~cm}$ but some were slightly larger or smaller (up to $5 \mathrm{~cm}$ in any one dimension). Their walls were pale brown and they were floored with absorbent pale blue paper. In some weeks the chicks were kept in a laboratory and incubated by suspending a light bulb just above each box; in other weeks they were kept in a constant temperature room $\left(25^{\circ} \mathrm{C}\right)$ under constant illumination. Undyed (pale brown) crumbs of a range of sizes extending both below $2.0 \mathrm{~mm}$ and above $2.4 \mathrm{~mm}$ were supplied ad libitum until 17.00 on day 6 . Water was constantly available.

In each trial, 500 dyed crumbs were scattered over the floor of the trial box. The chick was placed in the box and left for 2 hours, after which the remaining crumbs were counted. Trials were of four types, according to the palatability of the crumbs (distasteful or palatable) and to the ratio of green to brown $(9: 1$ or $1: 9)$. Each type was replicated five times in each block.

\section{(ii) Statistical analysis}

In addition to the method used for experiment one, experiment two was analysed in terms of the model of Greenwood and Elton (1979), which measures overall selection at the end of the trial, rather than instantaneous preference. The measure is in terms of two parameters: $V$ is a measure of frequency-independent preference and $b$ is a measure of frequencydependence. (This method could not be applied to experiment one because there were too many cases where all the red pastries were eaten.)

\section{(iii) Results}

Table 2 shows the mean $\beta$ values for the four treatments. It is clear from the grand mean that there was an insignificant tendency for green to

TABLE 2

Mean preferences $(\beta)$ for green crumbs shown by chicks in experiment two

$\begin{array}{lccc} & \text { Ratio of green to brown } & \\ & 1: 9 & 9: 1 & \text { Mean } \\ \text { Crumbs edible } & 0.242 & 0.676 & 0.459 \\ \text { Crumbs distasteful } & 0.295 & 0.569 & 0.432 \\ \text { Mean } & 0.268 & 0.622 & 0.446\end{array}$

be taken less than brown. The marginal totals show that selection was almost unaffected by the edibility of the crumbs but that green tended to be taken when common $(\beta>0.5)$ but not taken when rare $(\beta<0.5)$. The individual treatment means show that this frequency-dependent effect was less marked when the crumbs were distasteful than when they were edible. These conclusions are confirmed by analysis of variance (table 3 ). Thus the chicks tended to ignore the rarer colour not only when feeding on edible crumbs but also when feeding on distasteful crumbs, though the effect was less strong in the latter circumstances.

The results of these preferences, in terms of the model of Greenwoood and Elton (1979), are shown in table 4. As one would expect, they indicate 
TABLE 3

Analysis of variance for the preferences shown by chicks in experiment two

\begin{tabular}{lccccc}
\multicolumn{1}{c}{ Source } & Sum of squares & Degrees of freedom Mean square & F & P \\
Total & 6.619 & 78 & 0.085 & - & - \\
Error & 3.294 & 72 & 0.046 & - & - \\
Blocks & 0.109 & 3 & 0.036 & 0.78 & 0.5 \\
Treatments & 3.216 & 3 & 1.072 & 26 & $<10^{-6}$ \\
Interaction & 0.261 & 1 & $0 \cdot 261$ & $5 \cdot 7$ & $0 \cdot 02$ \\
Edibility & 0.001 & 1 & 0.001 & 0.02 & 0.9 \\
Frequency & 2.952 & 1 & 2.952 & 65 & $<10^{-6}$
\end{tabular}

Variance ratios are all calculated relative to the error mean square since the treatments are fixed.

Note that, because one chick ate no crumbs, the experiment was not orthogonal: the sums of squares for each main effect were calculated allowing for the other main effect. Because 12 chicks ate crumbs of one colour only, 12 of the $\beta$ values are zero or unity, so the data are not Normal. However, omission of the first week's data, which contain 7 of these 12 values, makes no substantial difference to the results of the analysis.

apostatic selection $(b>1)$, stronger for edible than distasteful crumbs, and a general frequency-independent selection of browns $(V>1)$. Unfortunately, the parameter estimates have wide confidence limits because the between-block variance could not be removed in this analysis.

\section{Discussion}

It is generally accepted that, because predators have to take a disproportionate number of a rarer form of prey before they learn that it is distasteful, rare forms are at a selective disadvantage in distasteful species. However, there is no experimental evidence for this view and our results show that it is not always true. There are some circumstances in which selection is only slightly, if at all, frequency-dependent and others in which the rare forms are at an advantage.

In experiment one, the number of items eaten was fewer than one would expect given the usual avidity with which wild passerines eat pastry baits and that with which they consumed the bread scattered near the baits. In experiment two, an average of 75 crumbs was eaten in trials with distasteful crumbs compared with 245 in trials with palatable crumbs. There is thus no doubt that the birds found the food items distasteful. Why, therefore, did they fail to behave as expected?

TABLE 4

Parameter estimates for the model of Greenwood and Elton (1979) applied to the data of experiment two

$\begin{array}{lcc} & b & V \\ \text { Crumbs edible } & 1.30 & 1 \cdot 50 \\ \text { Crumbs distasteful } & (0 \cdot 81-1 \cdot 79) & (0 \cdot 73-3 \cdot 07) \\ & 1 \cdot 19 & 1.41 \\ & (0.99-1.39) & (1.01-1.96)\end{array}$

95 per cent confidence limits are shown in brackets. 
The distastefulness of a food item to an animal is presumably the evolutionary product of selection resulting from the presence of toxic substances in some types of food. Animals would be expected to find distasteful those substances that have proved toxic during their evolutionary past plus gustatory mimics of such substances. Thus the distastefulness of a food item indicates the likely cost associated with eating it. If this cost exceeds the benefit derived from the nutritional value of the item, the animal should avoid eating similar items in future. It may, of course, need more than one experience of a particular type of food before it can assess the costs and benefits associated with that type or before it can learn to recognise it. However, if this number is roughly constant for the different morphs of a food species, then the predator will impose frequency-dependent selection against the rarer morphs. However, this assumes that the benefits to be derived from the food are constant. If an animal has not fed for some time the benefits of eating a noxious food item may outweigh the costs. The animal should eat the item and any similar ones it encounters until it has eaten so many that the benefits of eating another no longer outweigh the costs. Up to that point, it should select its diet efficiently, which under many circumstances may mean selecting apostatically (S. F. Hubbard et al., in prep.).

Variation in hunger between individual predators may mean that while some deliberately feed on the distasteful food, and select apostatically, others only feed on it while learning about it, and so select anti-apostatically. Thus, depending on the relative numbers of more hungry and less hungry predators, the overall result may be weaker apostatic selection than when the food is palatable, as in our second experiment, or no detectable frequency-dependent selection at all, as in our first experiment, or antiapostatic selection, as in the traditional hypothesis.

Our results, and the hypothesis based on them, thus allow one to use selection by predators to explain not only the general monomorphism of distasteful species but also their occasional polymorphism, such as in Danaus chrysippus (e.g., Smith, 1980). It may be objected that apostatically-selecting predators not only select against commonness but also against conspicuousness, so that one might expect polymorphic distasteful species not to be so evidently aposematic as monomorphic distasteful species. However, predators eating distasteful prey tend to take more of the inconspicuous forms than of the conspicuous forms (J. M. Lambert and J. J. D. Greenwood, in prep.). Thus the advantage which an inconspicuous form has while the predators are hungry may be outweighed when the predators are not hungry because they continue to eat the inconspicuous form but ignore the aposematic form that they recognise as distasteful.

There are other hypotheses to explain polymorphism in distasteful species. Suppose that such a species is eaten by a variety of predators, some treating it as distasteful and others treating it as palatable. The former will promote aposematism and monomorphism, the latter will promote inconspicuous colouration and polymorphism. Edmunds (1969) postulates that this can produce an aposematic polymorphic prey population. However, it is not clear how, on this hypothesis, aposematism can be disassociated from monomorphism and vice versa. If the first group of predators is more important than the second, then both aposematism and 
monomorphism will result; if the second group is more important, inconspicuous colouration and polymorphism will result. Our hypothesis is subtly different from this, in that the same predator individuals are responsible for promoting aposematism and polymorphism.

Another hypothesis to explain polymorphism in distasteful species is that it represents a response to mimicry (Owen and Chanter, 1968). Suppose that an aposematic monomorphic species has a mimic. It may suffer some predation because of predators that have experienced the minmic and which therefore expect at least some animals of that colour form to be edible. A new morph in the model will not suffer such predation, though it may suffer predation because it is rare (following the classical hypothesis). If the first effect is stronger than the second, then the new form will increase in frequency. However, this hypothesis does not explain the persistence of stable polymorphisms of models in which each morph has a mimic. In this situation, any morph that, for some reason, becomes rare compared with its mimic will suffer heavier predation than the other morphs and thus will become even rarer. Thus mimicry promotes the emergence of new morphs but destabilised polymorphism.

Of course, the selective forces acting on particular polymorphisms may be more complex than supposed in our simple hypothesis. Thus Danaus chrysippus is a common member of a large complex of Müllerian and Batesian mimics (Rothschild et al., 1975). Furthermore, there is evidence for pleiotropic effects of the colour genes, non-random mating and sexual selection, meiotic drive and sex-ratio polymorphism, and other types of selection, with the selective forces varying seasonally, possibly according to population-density and morph-frequency (Smith, 1973a, $b, 1975 a, b$, $1976 a, b, 1979,1980)$. Finally, the polymorphism may result from recent hybridisation of previously allopatric monomorphic races (Smith, 1975c, 1980).

If our hypothesis is the correct general explanation for polymorphism in some distasteful species, one would expect polymorphism to occur in those distasteful species that are among the less distasteful and that occur in situations where alternative food is scarce. Such predictions can only be tested by extensive work on actual distasteful animals. One would also expect that, in experiments such as we have reported here, the amount of predation and form of selection should be easily modified by varying the amount and palatability of alternative food available. We plan to carry out such experiments.

Acknowledgements.-We are grateful to all those friends who allowed us to carry out experiment one on their lawns; to colleagues in the Department of Biological Sciences, Dundee University, for various support-especially to Mrs Gillian Blyth for typing; and to Drs L. M. Cook, M. Edmunds, and S. F. Hubbard and an anonymous referee for criticising an earlier draft of this paper.

\section{REFERENCES}

BENSON, w. W. 1972. Natural selection for Müllerian mimicry in Heliconius erato in Costa Rica. Science, 176, 936-939.

CURIO, E. 1976. The Ethology of Predation. Springer, Berlin, Heidelberg and New York.

EDMUNDS, M. 1969. Polymorphism in the mimetic butterfly Hypolimnas misippus L. in Ghana. Heredity, 24, 281-302. 
Edmunds, M. 1974. Defence in Animals. Longman, Harlow.

FORD, H. A. 1971. The degree of mimetic protection gained by new partial mimics. Heredity, 27, 227-236.

GiTTLEMAN, J. L., AND HARVEY, P. H. 1980. Why are distasteful prey not cryptic? Nature, 256, $149-150$.

GITTLEMAN, J. L., HARVEY, P. H., AND GREENWOOD, P. J. 1980. The evolution of conspicuous coloration: some experiments in bad taste. Anim. Behaviour, 28, 897-899.

GREENWOOD, J. J. D. The nature of aposematic coloration. (In prep.)

GREENWOOD, J. J. D., AND ELTON, R. A. 1979. Analysing experiments on frequencydependent selection by predators. J. Anim. Ecol., 48, 721-737.

HARVEY, P. H., AND GREENWOOD, P. J. 1978. Anti-predator defence strategies: some evolutionary problems. In Behavioural Ecology, ed. J. R. Krebs and N. B. Davies. Blackwell, Oxford.

HUBbARD, S. F., GREENWOOD, J. J. D., GloVER, J. G., AND COOK, R. M. Is frequencydependent selection an optimal foraging strategy? (In prep.)

LAMBERT, J. M., AND GREENWOOD, J.J.D. Why are distasteful prey conspicuous? (In prep.) MANLY, B. F. J. 1973. A linear model for frequency-dependent selection by predators. Res. Popul. Ecol., 14, 137-150.

MANLY, B. F. J. 1974. A model for certain types of selection experiments. Biometrics, 30 , 281-294.

MURDOCH, W. W., AND OATEN, A. 1975. Predation and population stability. Adv. Ecol. Research, 9, 1-131.

OWEN, D. F. AND CHANTER, D. O. 1968. Population biology of tropical African butterflies. 2. Sex ratio and polymorphism in Danaus chrysippus L. Revue Zool. Bot. Afr., 78, 81-97.

ROTHSCHILD, M., VON EUW, J., REICHSTEIN, J., SMITH, D. A. S., AND PIERRE, J. 1975. Cardenolide storage in Danaus chrysippus (L) with additional notes on D. plexippus (L). Proc. roy. Soc. Lond, B, 190, 1-31.

SHETTLEWORTH, S. J. 1972. The role of novelty in learned avoidance of unpalatable "prey" by domestic chicks (Gallus gallus). Anim. Behaviour, 20, 29-35.

SMITH, D. A. S. 1973 a. Batesian mimicry between Danaus chrysippus and Hypolimnas misippus (Lepidoptera) in Tanzania. Nature, Lond., 242, 129-131.

SMITH, D. A. S. $1973 b$. Negative non-random mating in the polymorphic butterfly Danaus chrysippus in Tanzania. Nature, Lond, 242, 131-132.

SMITH, D. A.S. 1975 a. Sexual selection in a wild population of the butterfly Danaus chrysippus L. Science, Wash., 187, 664-665.

SMITH, D. A. S. 1975 b. All-female broods in the polymorphic butterfly Danaus chrysippus L. and their ecological significance. Heredity, 34, 363-371.

SMITH, D. A. S. 1975 c. Genetics of some polymorphic forms of the African butterfly Danaus chrysippus L. (Lepidoptera: Danaidae). Ent. Scand. 6, 134-144.

SMITH, D. A. S. $1976 a$. Evidence for autosomal meiotic drive in the butterfly Danaus chrysippus L. Heredity, 36, 139-142.

SMITH, D. A. S. $1976 b$. Phenotypic diversity, mimicry and natural selection in the African butterfly Hypolimnas misippus L. (Lepidoptera: Nymphalidae). Biol. J. Linn. Soc. Lond., 8, 183-204.

SMITH, D. A.S. 1979. The significance of beak marks on the wings of an aposematic, distasteful and polymorphic butterfly. Nature, Lond. 281, 215-216.

SMITH, D. A. S. 1980. Heterosis, epistasis and linkage disequilibrium in a wild population of the polymorphic butterfly Danaus chrysippus (L). Zool. J. Linn. Soc. Lond., 69, 87-109.

TURNER, J. R. G. 1975. Butterfly mimicry: the genetical evolution of an adapatation. Evol. Biol, , 10, 163-206.

WICKLER, W. 1968. Mimicry. Weidenfeld and Nicolson, London. 